УДК 620.92

\title{
ЭНЕРГЕТИЧЕСКИЙ И ЭКОЛОГИЧЕСКИЙ АНАЛИЗ ТЕХНОЛОГИЙ ПРОИЗВОДСТВА ЭНЕРГИИ ИЗ БИОМАССЫ. ЧАСТЬ 2.
}

Гелетуха Г.Г., канд. тех. наук, Железная Т.А., канд. тех. наук, Дроздова О.И.

Институт технической теплофизики НАН Украины, ул. Желябова, 2a, 03680, Киев, Украина

Розглянуто питання енергетичної ефективності технологій виробництва біогазу та рідких біопалив першого покоління. Оцінено рівень скорочення викидів парникових газів при заміщенні традиційних палив біомасою.
Рассмотрен вопрос энергетической эффективности технологий производства биогаза и жидких биотоплив первого поколения. Оценен уровень сокращения выбросов парниковых газов при замещении традиционных топлив биомассой.
The paper covers the issue of energy efficiency of biogas production and production of first generation liquid biofuels. Assessment of GHG balance when replacing fossil fuels by biomass is performed.

Библ. 8, табл. 6, рис. 1.

Ключевые слова: биомасса, биогаз, биотопливо, биоэнергетические технологии, энергетический анализ, коэффициент выхода энергии, оценка жизненного цикла, парниковый газ.

$Q_{\mathrm{BE}}$ - теплотворная способность биоэтанола;

БГ - биогаз;

БГУ - биогазовая установка;

ПГ - парниковый газ;

\section{Энергетическая эффективность производство биогаза}

Оценка жизненного цикла технологий производства биогаза выполнена в работе [1] для условий Германии. Рассмотрено получение биогаза из силоса кукурузы с последующим производством электрической энергии двигателем мощностью 255 кВт . Для трех районов Нижней Саксонии проанализировано влияние местных условий, в первую очередь качества почвы, климатических условий, применяемой технологии выращивания и, соответственно, урожайности кукурузы на энергетические и экологические показатели биогазовых технологий. Другим важным фактором, который влиял на результаты исследования, была доля полезно утилизированной тепловой энергии, которая считалась побочным продуктом работы БГУ.

Проведенные расчеты показали, что энергетическая эффективность исследованных технологий производства биогаза находится на грани допустимых значений. Величина коэффициента выхода энергии $E Y C_{N R}$ для всех рассмотренных вариантов колеблется в районе 2 (меньше ре-
ФТ - Фишер-Тропш;

ТБО - твердые бытовые отходы;

э/э - электроэнергия;

у.т. - условное топливо.

комендуемого значения для биоэнергетических технологий) (табл. 1). Самый высокий показатель $(2,2)$ получен для биогазовой установки в Göttingen, где затраты невозобновляемой энергии на выращивание кукурузы наименьшие, а доля полезной утилизации тепловой энергии наибольшая.

Для БГУ, работающих на кукурузе, установлено, что из общего объема ископаемой энергии "на входе" наибольшая доля (до 70 \%) тратится собственно на выращивание кукурузы. Еще часть ископаемой энергии (до 30 \%) расходуется на транспортировку биомассы к месту хранения (силосные кагаты) и загрузку в биореактор (принятое в исследовании среднее расстояние перевозки - 20 км). Собственные нужды биогазовых установок (электроэнергия на привод мешалок, насосов и т.д., а также тепловая энергия для обогрева биореакторов) обычно в полной мере обеспечиваются за счет части энергии производимого биогаза (до $15 \ldots 25 \%$ ). Эта информация может быть полезной при оптимизации энергозатрат «на входе» БГУ для обеспечения более высокого коэффициента выхода энергии. 
Табл. 1. Характеристики исследуемых вариантов производства электроэнергии из биогаза [1]

\begin{tabular}{|c|c|c|c|}
\hline Показатели & $\begin{array}{c}\text { Вариант I } \\
\text { (paйон Göttingen) }\end{array}$ & $\begin{array}{c}\text { Вариант II } \\
\text { (район Celle) }\end{array}$ & $\begin{array}{c}\text { Вариант III } \\
\text { (район Hildesheim) }\end{array}$ \\
\hline $\begin{array}{l}\text { Потребление ископаемых топлив на } \\
\text { выращивание кукурузы, кг у.т./т силоса }\end{array}$ & 5,8 & 8,2 & 6,2 \\
\hline $\begin{array}{l}\text { Потребление э/э на собственные нужды } \\
\text { БГУ, \% произведенной э/э }\end{array}$ & $7 \%$ & $7 \%$ & $7 \%$ \\
\hline $\begin{array}{l}\text { Потребление тепловой энергии на } \\
\text { собственные нужды БГУ, кВт·час/м³ } \\
\text { биогаза }\end{array}$ & 0,256 & 0,256 & 0,256 \\
\hline $\begin{array}{l}\text { Доля полезно утилизированной тепло- } \\
\text { вой энергии }\end{array}$ & $60 \%$ & $30 \%$ & $40 \%$ \\
\hline$E Y C_{N R} *$ & 2,2 & 1,84 & 2,1 \\
\hline
\end{tabular}

* Пересчет авторов по данным работы [1].

Табл. 2. Характеристики биогазовых установок, работающих на разных видах сырья [2]

\begin{tabular}{|c|c|c|c|c|c|c|}
\hline \multirow[b]{2}{*}{ Вид сырья } & \multirow[b]{2}{*}{$\begin{array}{c}\text { Содержание } \\
\text { сухого } \\
\text { вещества, \% }\end{array}$} & \multirow[b]{2}{*}{$\begin{array}{l}\text { Выход БГ } \\
\text { ГДж/сух. т }\end{array}$} & \multicolumn{3}{|c|}{ Затраты энергии «на входе», ГДж/сух. т } & \multirow[b]{2}{*}{$E Y C_{N R}$} \\
\hline & & & $\begin{array}{c}\text { Подготовка } \\
\text { сырья }\end{array}$ & $\begin{array}{c}\text { Транспорти- } \\
\text { ровка сырья } \\
(15 \text { км) }\end{array}$ & $\begin{array}{c}\text { Доставка } \\
\text { сброженного } \\
\text { остатка на } \\
\text { поля }\end{array}$ & \\
\hline Коровий навоз & 8 & 6,2 & 0 & 0,19 & 0,15 & 2,6 \\
\hline Свиной навоз & 8 & 7 & 0 & 0,19 & 0,15 & 3,0 \\
\hline Жировые осадки & 4 & 22 & 0 & 1,2 & 0,24 & 6,2 \\
\hline $\begin{array}{l}\text { Энергетические } \\
\text { культуры }\end{array}$ & 23 & 10,6 & 1,9 & 0,07 & 0,24 & 2,4 \\
\hline $\begin{array}{l}\text { Органическая часть } \\
\text { ТБО }\end{array}$ & 30 & 12,4 & 0,8 & 0,24 & 0,24 & 3,6 \\
\hline Отходы скотобойни & 17 & 9,4 & 0 & 0,14 & 0,24 & 3,6 \\
\hline $\begin{array}{l}\text { Ботва сахарной } \\
\text { свеклы }\end{array}$ & 19 & 10,6 & 0,54 & 0,09 & 0,24 & 3,5 \\
\hline Солома & 82 & 7,1 & 0,28 & 0,05 & 0,24 & 2,7 \\
\hline
\end{tabular}

Можно ожидать, что для биогазовых установок $E Y C_{N R}$ будет выше 2 для случаев использования в качестве сырья большей доли отходов сельского хозяйства или других видов отходов. Этот вывод подтверждается данными исследования [2], где была рассмотрена энергетическая эффективность БГУ, работающих на разных видах сырья для условий Швеции. Наилучший результат $\left(E Y C_{N R}=6,2\right)$ получен для случая производства биогаза из жировых осад- ков (таблица 2). Этому виду сырья соответствует наивысший удельный выход биогаза 22 ГДж/сух. т и нулевые затраты на подготовку биомассы. Самый низкий коэффициент выхода энергии $(2,4)$ приходится на энергетические культуры как сырье для получения биогаза. Этот вариант имеет наибольшие затраты энергии на подготовку сырья, поскольку включает этап выращивания культур, и средний выход биогаза 10,6 ГДж/сух. т. 


\section{Энергетическая эффективность производства биоэтанола и биодизеля}

Обычно много споров вызывает вопрос целесообразности производства биотоплив первого поколения, в частности биоэтанола. Рассмотрим несколько весомых исследований, посвященных этому вопросу.

В работе [3] оценено энергетическую эффективность различных технологий производства биоэтанола (для условий Франции). Проанализировано три случая: I - производство биоэтанола из сахарной свеклы с побочным продуктом - бардой, II - производство биоэтанола из сахарной свеклы с сахаром как «побочным» продуктом, III - производство биоэтанола из зерна пшеницы с побочным продуктом - сухой дробиной с растворимыми веществами. Для каждого случая были рассмотрены несколько вариантов распределения затраченной энергии (т.е. энергии «на входе») между основным и побочными продуктами производства: по их массе, по содержанию энергии, по рыночной стоимости, по энергии, необходимой для производства заменителя по- бочного продукта (энергия «замещения»). На сегодня не существует единого мнения специалистов относительно того, какой метод распределения энергозатрат является наилучшим. Но чаще всего применяют метод распределения по массе конечных продуктов.

Результаты расчета показывают, что коэффициент выхода энергии $E Y C_{N R}$ существенно отличается для различных технологий получения биоэтанола и зависит также от способа распределения «входящих» энергозатрат по конечным продуктам (таблица 3).

При производстве биотоплива из сахарной свеклы для всех рассмотренных вариантов $E Y C_{N R}<2$, а при методах распределения энергозатрат не по массе конечных продуктов даже < 1. Это свидетельствует об очень низкой энергетической эффективности получения биоэтанола или вообще об ее отсутствии. Единственный положительный результат дает вариант производства биотоплива из пшеницы с распределением «входящих» энергозатрат по массе конечных продуктов - биоэтанола и сухой дробины. В этом случае коэффи-

Табл. 3. Энергетическая эффективность технологий производства биоэтанола [3]

\begin{tabular}{|l|c|c|c|c|}
\hline \multirow{2}{*}{$\begin{array}{c}\text { Метод распределения энергозатрат } \\
\text { по конечным продуктам }\end{array}$} & \multicolumn{2}{|c|}{ Биоэтанол из сахарной свеклы** } & $\begin{array}{c}\text { Биоэтанол из } \\
\text { пшеницы }\end{array}$ \\
\cline { 2 - 5 } & Вариант I & $\begin{array}{c}\text { Вариант } \\
50 \text { \% I 50 \% II }\end{array}$ & Вариант II & Вариант III \\
\cline { 2 - 5 } & $E Y C_{N R}$ & $E Y C_{N R}$ & $E Y C_{N R}$ & $E Y C_{N R}$ \\
\hline $\begin{array}{l}\text { Без распределения - все отнесено } \\
\text { на биоэтанол }\end{array}$ & 1,42 & 0,54 & 0,33 & 0,83 \\
\hline По массе* & 1,59 & 1,28 & 1,02 & 2,23 \\
\hline По содержанию энергии & 1,51 & 1,13 & 0,89 & 1,52 \\
\hline По рыночной стоимости & 1,47 & 1,22 & 0,98 & 1,77 \\
\hline $\begin{array}{l}\text { По энергии, необходимой для } \\
\text { производства заменителя } \\
\text { побочного продукта }\end{array}$ & 1,48 & 1,12 & 0,88 & 0,96 \\
\hline
\end{tabular}

* Наиболее распространённый вариант распределения энергозатрат.

** Варианты производства биоэтанола: I - из сахарной свекльг с бардой как побочнылм продуктом, II - из сахарной свекль с сахаром как «побочным» продуктом, III-из зерна пшениџы с сухой дробиной с растворимыми веществами как побочным продуктом. 
циент выхода энергии $E Y C_{N R}>2$, что удовлетворяет минимальным требованиям по энергетической эффективности биоэнергетических технологий.

Представляет значительный интерес исследование [4], в котором проведен детальный анализ полной энергоемкости производства биоэтанола и биодизеля по существующим технологиям для условий Украины. Рассмотрены варианты получения биоэтанола из озимой пшеницы, ярового ячменя и сахарной свеклы. Результаты оценки показывают, что при использовании технологии вакуумной ректификации, энергозатраты на производство биоэтанола из всех рассмотренных видов сырья практически равны энергосодержанию полученного биотоплива $\left(E Y C_{N R} \approx 1\right)$ (табл. 4). При использовании же технологии атмосферной ректификации, затраты энергии на производство биоэтанола превышают его энергосодержание $\left(E Y C_{N R}<1\right)$.

Таким образом, авторы [4] делают вывод, что данное направление получения биотоплива нельзя считать энергетически целесообразным. Оно может иметь только локальное значение в случае, когда сырье для производства биоэтанола является отходом, подлежащим утилизации или уничтожению. Или другими словами, когда затраты энергии на транспортировку и подготовку сырья незначительны и не превышают 4...5 МДж/л.
Относительно биодизельного топлива в исследовании [4] рассматривается случай его производства из рапсового масла путем переэтерификации масла метиловым спиртом. Оценено, что полная энергоемкость производства биотоплива составляет 23,5...29,3 МДж/кг. Исходя из энергетической емкости биодизеля 40 МДж/кг, эти показатели соответствуют коэффициенту выхода энергии $E Y C_{N R}=1,36 \ldots 1,70$. Авторы [4] отмечают, что с учетом энергетического эквивалента факторов, вызванных физическим трудом людей, амортизацией оборудования и сооружений, финансовыми и другими затратами, полная энергоемкость производства биодизеля из рапсового масла составит $40 \ldots 50$ МДж/кг $\left(E Y C_{N R}=0,8 \ldots 1,0\right)$. Это означает, что производство биодизеля также является нечелесообразным с энергетической точки зрения.

\section{Экологический анализ}

Снижение выбросов парниковых газов является одним из наиболее весомых показателей при оценке влияния биоэнергетических технологий на окружающую среду. И хотя биомасса считается $\mathrm{CO}_{2}$-нейтральным топливом, при операциях ее заготовки, складирования, транспортировки, предварительной обработки и использования происходит потребление энергии ископаемого топлива, что в свою очередь приводит к выбросам парниковых газов. Основными парниковыми газами, выбро-

Табл. 4. Энергетические показатели технологий производства биоэтанола [4]

\begin{tabular}{|l|c|c|c|c|}
\hline \multirow{2}{*}{ Сырье } & \multicolumn{2}{|c|}{ Полные энергозатраты*, МДж/л } & \multicolumn{2}{c|}{ Коэффициент выхода энергии $E Y C_{N R}$} \\
\cline { 2 - 5 } & $\begin{array}{c}\text { Атмосферная } \\
\text { ректификация } \\
C E D 1\end{array}$ & $\begin{array}{c}\text { Вакуумная } \\
\text { ректификация } \\
C E D 2\end{array}$ & $\begin{array}{c}\text { Атмосферная } \\
\text { ректификация } \\
Q_{B E} / C E D 1\end{array}$ & $\begin{array}{c}\text { Вакуумная } \\
\text { ректификация } \\
Q_{B E}\end{array}$ \\
\hline Озимая пшеница & 28,58 & 22,88 & 0,8 & 1,0 \\
\hline Ярый ячмень & 25,58 & 19,88 & 0,9 & 1,1 \\
\hline Кукуруза & 27,39 & 21,69 & 0,8 & 1,0 \\
\hline Сахарная свекла & 29,7 & 24,3 & 0,8 & 0,9 \\
\hline
\end{tabular}

* Учтены все технологические (физические) затратыл. Не учтены энергозатраты, связанные с работой людей, амортизацией оборудования и т.п. 
сы которых имеют место при работе энергетических систем являются диоксид углерода $\left(\mathrm{CO}_{2}\right)$, метан $\left(\mathrm{CH}_{4}\right)$ и закись азота $\left(\mathrm{N}_{2} \mathrm{O}\right)$. Величина выбросов всех парниковых газов приводится к эквивалентному показателю выбросов $\mathrm{CO}_{2}$ через соответствующие коэффициенты.

Ниже рассмотрим величину сокращения выбросов парниковых газов для различных биоэнергетических технологий по сравнению с установками на ископаемых топливах, и соответствует ли она требованиям Директивы 2009/28/EC [6]. Напомним, что согласно этой Директиве, снижение выбросов парниковых газов при внедрении технологий возобновляемой энергетики должно быть не менее $35 \%$ по сравнению с аналогичным использованием ископаемых топлив. С 01.01.2017 минималь- ное требование увеличивается до $50 \%$, а с 01.01.2018 - до 60 \% для установок, введенных в эксплуатацию с 01.01.2017.

В таблице 5 представлены результаты исследования [7], проведенного в рамках Задачи 38 Международного Энергетического Агентства, собственные результаты авторов и данные по типичным выбросам парниковых газов при производстве биотоплив согласно Директиве 2009/28/EC.

Из данных таблицы видно, что все установки на твердой биомассе и большинство установок на биогазе соответствуют текущим и будущим требованиям Директивы 2009/28/ ЕС - сокращение выбросов парниковых газов, обусловленное их работой, составляет $>60 \%$.

Что касается жидких моторных биотоплив,

Табл. 5. Удельные выбросы парниковых газов для различных технологий производства энергии из биомассы

\begin{tabular}{|c|c|c|c|}
\hline Виды технологий & $\begin{array}{c}\text { Удельные выбросы } \\
\text { ПГ }\end{array}$ & \multicolumn{2}{|c|}{ Сокращение выбросов ПГ } \\
\hline Производство тепловой энергии & $\Gamma \mathrm{CO}_{2-э к \mathrm{~B}} / \mathrm{KBT} \cdot \Psi_{\mathrm{T}}$ & $\Gamma \mathrm{CO}_{2-э \kappa \mathrm{B}} / \mathrm{KBT} \cdot \mathrm{\Psi}_{\mathrm{T}}$ & $\%$ \\
\hline Котел на отходах древесины (150 кВт $)$ [7] & 52 & 327 & $86 \% 1)$ \\
\hline Котел на мискантусе $(70$ кВт $)$ [7] & 101 & 295 & $75 \%{ }^{1)}$ \\
\hline Котел на древесной щепе $(500 \text { кВт })^{4)}$ & 39 & 185 & $83 \%$ \\
\hline $\begin{array}{l}\text { Котел на древесной щепе из энергетической } \\
\text { вербы }(300 \text { кВт) })^{4}\end{array}$ & 39 & 185 & $83 \%$ \\
\hline Котел на тюках соломы $(500 \text { кВт })^{4)}$ & 14 & 211 & $94 \%$ \\
\hline Котел на гранулах из древесины $(100 \text { кВт })^{4)}$ & 33 & 194 & $85 \%$ \\
\hline Котел на гранулах из соломы $(100 \text { кВт) })^{4}$ & 60 & 165 & $72 \%$ \\
\hline Производство электроэнергии & $\Gamma \mathrm{CO}_{2-э к \mathrm{~B}} / \kappa \mathrm{BT} \cdot \mathrm{\Psi}_{\ni}$ & $\Gamma \mathrm{CO}_{2-э к в} / \kappa \mathrm{BT}^{\cdot} \Psi_{\ni}$ & $\%$ \\
\hline ТЭС на древесной щепе $\left(2 \mathrm{MBT}_{э}\right)^{4)}$ & 213 & 909 & $81 \%$ \\
\hline ТЭС на тюках соломы $\left(2 \mathrm{MB}_{\ni}\right)^{4)}$ & 217 & 905 & $80 \%$ \\
\hline ТЭС на тюках соломы (25 $\left.\mathrm{MBT}_{э}\right)[8]^{9)}$ & $178^{10)}$ & нет данных & $65 \%$ \\
\hline ТЭС на отходах древесины (30 MBт $)$ [7] & 71 & 950 & $93 \%{ }^{2)}$ \\
\hline 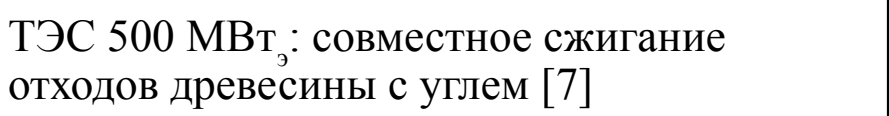 & 128 & 881 & $87 \%{ }^{2)}$ \\
\hline
\end{tabular}




\begin{tabular}{|c|c|c|c|}
\hline $\begin{array}{c}\text { Совместное производство тепловой } \\
\text { и электрической энергии }\end{array}$ & $\Gamma \mathrm{CO}_{2-э к в} / \mathrm{KBT}^{\cdot} \cdot \mathrm{\Psi}_{\text {об. }}$ & $\Gamma \mathrm{CO}_{2-э к в} / \kappa \mathrm{BT} \cdot \Psi_{\text {об. }}$ & $\%$ \\
\hline $\begin{array}{l}\text { БГУ с совместным сбраживанием навоза } \\
\text { и силоса кукурузы (годовое производство э/э } \\
4 \text { ГВт·ч, тепловой энергии 7,2 ГВт·ч) [7] }\end{array}$ & 266 & 207 & $56 \%{ }^{3)}$ \\
\hline ТЭЦ на древесной щепе $\left(2 \mathrm{MBT}_{э}+10 \mathrm{MBT}_{\mathrm{T}}\right)^{4)}$ & 35 & 152 & $81 \%$ \\
\hline ТЭЦ на тюках соломы $\left(2 \mathrm{MBT}_{э}+10 \mathrm{MBT}_{\mathrm{T}}\right)^{4)}$ & 37 & 150 & $80 \%$ \\
\hline Моторные биотоплива $[1]^{5)}$ & г $\mathrm{CO}_{2-э к в} / \mathrm{M}$ Дж & & \\
\hline Биогаз из навоза ${ }^{8)}$ & $12 \ldots 13$ & & $84 \ldots 86 \%$ \\
\hline Биогаз с полигонов ТБО ${ }^{8)}$ & 17 & & $80 \%$ \\
\hline \multicolumn{4}{|l|}{ Биотоплива I поколения } \\
\hline Биоэтанол из сахарной свеклы & 33 & & $61 \%$ \\
\hline Биоэтанол из пшеницы & 57 & & $32 \%$ \\
\hline Биоэтанол из кукурузы & 37 & & $56 \%$ \\
\hline Биодизель из рапса & 46 & & $45 \%$ \\
\hline \multirow{2}{*}{ Биодизель из рапса [7] } & $111 г \mathrm{CO}_{2-э к в} / \mathrm{KM}$ & 80 г $\mathrm{CO}_{2-э к в} / \mathrm{KM}$ & $58 \% 6)$ \\
\hline & 157 г $\mathrm{CO}_{2-э к в} / \mathrm{KM}$ & 34 г $\mathrm{CO}_{2-э к в} / \mathrm{KM}$ & $18 \% 7)$ \\
\hline Биодизель из подсолнечника & 35 & & $58 \%$ \\
\hline Биодизель из сои & 50 & & $40 \%$ \\
\hline \multicolumn{4}{|l|}{ Биотоплива II поколения } \\
\hline Биоэтанол из соломы пшеницы & 11 & & $87 \%$ \\
\hline Биоэтанол из древесных отходов & 17 & & $80 \%$ \\
\hline Биодизель ФТ & $4 \ldots 6$ & & $93 \ldots 95 \%$ \\
\hline
\end{tabular}

1) По сравнению с мазутным котлом.

2) По сравнению с угольной электростанщией.

3) По сравнению с газовой ТЭЦ.

4) Результаты авторов для условий Украинь (расстояние транспортировки биомассы - 50 км). Сравнение с вариантом сжигания природного газа.

5) Типичные значения согласно Приложению 5 Директивы 2009/28/ЕС [6].

6) Побочный продукт глищерин используется в качестве материала в пищевой или фармацевтической промышлености.

7) Побочный продукт глицерин используется как топливо.

8) В виде сжатого метана.

9) Данные для случая урожайности зерновых культур порядка 7 сух. m/га. Сравнение с вариантом сжигания природного газа.

10) Пересчет авторов по данным соответствующей работьл. 
то большинство показателей биодизеля и биоэтанола первого поколения удовлетворяют текущим требованиям Директивы 2009/28/EC, некоторые удовлетворяют требованию, которое вступит в силу с 2017 года (мин. 50 \%), и практически все показатели выходят за пределы требования, которое будет применяться с 2018 года (мин. 60 \%). Для биотоплив второго поколения результаты намного лучше - сокращение эмиссии парниковых газов составляет $80 \ldots 95 \%$. Хорошие показатели имеет также биогаз как моторное топливо - более 80 \%.

Эти результаты хорошо согласуются с данными других авторов, собранными и представленными в исследовании [7]. При производстве энергии из биомассы снижение выбросов парниковых газов составляет 70...90\% по сравнению с энергоустановками на ископаемых топливах. При применении моторных биотоплив первого поколения сокращение эмиссии ПГ незначительное. Наилучшие показатели имеют биоэтанол и биодизель второго поколения - для них уменьшение выбросов ПГ может достигать более 90 \%. Достаточно хороший показатель соответствует также случаю применения биогаза в качестве моторного топлива - в среднем около $65 \%$.

\section{Влияние расстояния транспортировки на энергетические и экологические показатели биоэнергетических технологий}

Как было отмечено ранее, одним из параметров, существенно влияющих на энергетическую эффективность внедрения биоэнергетических технологий, является расстояние транспортировки биомассы к месту ее обработки, конечного потребления и т.п.

Согласно данным работы [5], для сохранения энергетической эффективности биоэнергетической установки на минимально необходимом уровне $\left(E Y C_{N R}>2\right)$ древесную щепу можно перевозить на расстояние до 200...300 км, а древесные гранулы практически не имеют ограничения по расстоянию транспортировки. Если же энергоустановка на гранулах должна соответствовать критерию высокой энергетической эффективности $\left(E Y C_{N R}>5\right)$, то рас- стояние перевозки ограничивается радиусом порядка 1200 км.

Для получения более детальной информации авторы исследовали влияние расстояния транспортировки биомассы/биотоплива на коэффициент выхода энергии $E Y C_{N R}$ для условий Украины. Результаты расчетов для типичных установок показали, что тюкованную солому, древесную щепу и гранулы из биомассы можно перевозить на расстояние до 300 км с сохранением достаточно высокого коэффициент выхода энергии $\left(E Y C_{N R}>2\right)$ (рис. 1).

Предельные значения расстояния перевозки, соответствующие $E Y C_{N R}=1, E Y C_{N R}=2$ и $E Y C_{N R}=5$, представлены в таблице 6. Если коэффициент выхода энергии равен 1, это означает, что расходы (невозобновляемой) энергии, необходимые для создания и обеспечения работы биоэнергетической установки, эквивалентны энергии, полученной «на выходе». $E Y C_{N R}=2$ соответствует минимально допустимой энергетической эффективности работы установки, а $E Y C_{N R}=5$ и больше соответствует наиболее рекомендуемым значениям (по данным работы [5]).

Для варианта работы биоэнергетической установки (кроме ТЭС) на уровне энергоэффективности не ниже минимально рекомендованного $\left(E Y C_{N R}>2\right)$ расстояние перевозки биотоплива может быть довольно большим $500 \ldots 1000$ км в зависимости от вида биотоплива и типа установки. Если же необходимо обеспечить более высокий уровень энергоэффективности $\left(E Y C_{N R}>5\right)$, то расстояние транспортировки следует ограничить до 100...200 км, а в некоторых случаях - и до минимального значения. Следует отметить, что сделанные выводы носят общий характер, а в каждом конкретном случае необходимо выполнять детальные расчеты с тщательным учетом местных особенностей.

\section{Выводы}

Внедрение технологий производства энергии из биомассы предлагает широкие возможности для замещения ископаемых топлив. Определение целесообразности и приоритет- 


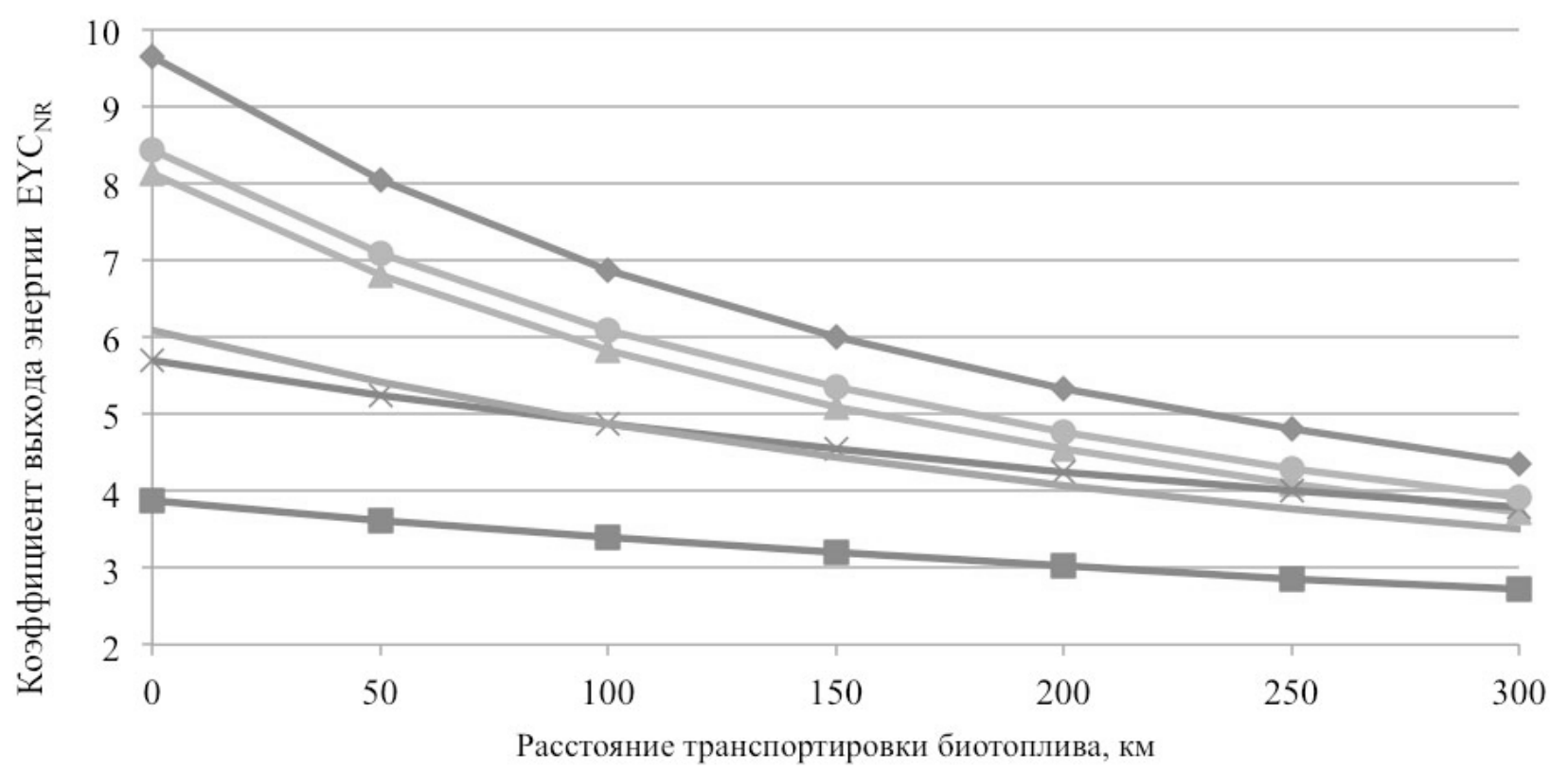

\footnotetext{
—Котел на соломе (500 кВт)

$\rightarrow$ Котел на древесной щепе (500 кВт)

— ТЭЦ на тюках соломы $\left(2 \mathrm{MBT}_{\text {эл }}+10 \mathrm{MBT}_{\mathrm{T}}\right)$

- Котел на гранулах из соломы (100 кВт)

× Котел на древесных гранулах (100 кВт)

$\multimap$ ТЭЦ на древесной щепе $\left(2 \mathrm{MBT}_{э л}+10 \mathrm{MBT}_{\mathrm{T}}\right)$

\section{Рис. 1. Зависимость коэффициента выхода энергии от расстояния транспортировки биотоплива.}

ности внедрения определенных технологий в конкретных условиях может основываться на результатах расчета энергетического баланса и баланса парниковых газов - основных элементов оценки жизненного цикла технологий.

Энергетическая эффективность работы биогазовых установок зависит от вида сырья, применяемой технологии и других условий. Согласно литературным данным, для БГУ коэффициент выхода энергии может колебаться от 1,8 до $>6$.

Ситуация с производством моторных биотоплив (биодизеля и биоэтанола) неоднозначная. По большинству имеющихся данных коэффициент выхода энергии для них существенно ниже 2, тогда как некоторые авторы показывают $E Y C_{N R}>2$. Представляется, что положительного с энергетической точки зрения результата можно достичь лишь в отдельных случаях при определенных условиях, например, при использовании сырья в виде отходов, подлежащих утилизации.
По вопросу экологической эффективности биоэнергетических технологий можно отметить, что все установки на твердой биомассе и большинство установок на биогазе соответствуют текущим и будущим требованиям Директивы 2009/28/ЕС - сокращение выбросов парниковых газов, обусловленное их работой, составляет $>60 \%$.

Что касается жидких моторных биотоплив, то большинство показателей биодизеля и биоэтанола первого поколения удовлетворяют текущим требованиям Директивы 2009/28/EC, некоторые удовлетворяют требованию, которое вступит в силу с 2017 года (мин. 50 \%), и практически все показатели выходят за пределы требования, которые будут применяться с 2018 года (мин. 60 \%). Для биотоплива второго поколения результаты намного лучше сокращение эмиссии парниковых газов составляет $80 \ldots 95$ \%. Хорошие показатели имеет также биогаз как моторное топливо - более $80 \%$. 
Табл. 6. Максимально целесообразное расстояние транспортировки биотоплив автотранспортом

\begin{tabular}{|c|c|c|c|}
\hline \multirow[b]{2}{*}{ Тип энергетической установки } & \multicolumn{3}{|c|}{ Предельное расстояние транспортировки, км } \\
\hline & $\begin{array}{c}E Y C_{N R}=1 \\
\text { энергия «на входе» } \\
\text { равна энергии } \\
\text { «на вьходе» }\end{array}$ & $\begin{array}{c}E Y C_{\text {NR }}=2 \\
\text { минимально } \\
\text { допустимое } \\
\text { значение }\end{array}$ & $\begin{array}{c}E Y C_{N R}=5 \\
\text { рекомендуемое } \\
\text { значение }\end{array}$ \\
\hline Котел на древесной щепе (500 кВт) & 1800 & 800 & 170 \\
\hline $\begin{array}{l}\text { Котел на древесной щепе из } \\
\text { энергетической вербы (300 кВт) }\end{array}$ & 2100 & 900 & 120 \\
\hline Котел на гранулах из древесины (100 кВт) & 2800 & 1100 & 80 \\
\hline ТЭЦ на древесной щепе $\left(2 \mathrm{MBT}_{\text {эл }}+10 \mathrm{MBT}_{\mathrm{T}}\right)$ & 1900 & 850 & 170 \\
\hline ТЭС на древесной щепе $\left(2 \mathrm{MB}_{\ni}\right)$ & 250 & 0 & $-*$ \\
\hline Котел на соломе $(500$ кВт) & 1800 & 800 & 200 \\
\hline Котел на гранулах из соломы (100 кВт) & 1800 & 500 & $-*$ \\
\hline ТЭЦ на тюках соломы $\left(2 \mathrm{MBT}_{э}+10 \mathrm{MBT}_{\mathrm{T}}\right)$ & 1500 & 800 & 80 \\
\hline ТЭС на тюках соломы (2 MBт $)$ & 150 & $-* *$ & $-*$ \\
\hline
\end{tabular}

* Даже при нулевом расстоянии перевозки биотоплива $E Y C_{N R}<5$.

** Даже при нулевом расстоянии перевозки биотоплива $E Y C_{N R}<2$.

\section{ЛИТЕРАТУРА}

1. Daniela Dressler, Achim Loewen, Michael Nelles. Life cycle assessment of the supply and use of bioenergy: impact of regional factors on biogas production // The International Journal of Life Cycle Assessment. - November 2012, vol. 17, issue 9, P. $1104-1115$.

2. M. Berglund, P. Börjesson. Energy analysis of biogas systems. Proc. of 2nd World Conference on Biomass for Energy, Industry and Climate Protection, 10-14 May 2004, Rome, Italy, P. $687-690$.

3. J. Malca, F. Freire. Life cycle energy analysis for bioethanol: allocation methods and implications for energy efficiency and renewability. Proceedings of 17 th International Conference on Efficiency, costs optimization simulation and environmental impact of energy and process systems, 7-9 July 2004, Mexico.

4. Белодед В.Д., Тарасенко П.В. Некоторые расчеты относительно энергетической эффективности биотоплив // Проблемы общей энер- гетики. - 2008, №18, С. 34 - 39 .

5. Thomas Nussbaumer, Michael Oser. Evaluation of biomass combustion based energy systems by cumulative energy demand and energy yield coefficient. Report for International Energy Agency and Swiss Federal Office of Energy, 2004.

6. Директива 2009/28/EC относительно стимулирования использования энергии из возобновляемых источников, внесения изменений и дальнейшего изменения Директив 2001/ 77/ЕС и 2003/30/ЕС.

7. Neil Bird, Annette Cowie, Francesco Cherubini, Gerfried Jungmeier. Using a Life Cycle Assessment approach to estimate the net greenhouse gas emissions of bioenergy. Report on IEA Bioenergy Task 38.

8. C.M. Sastre, E. Maletta, Y. Gonzalez-Arechavala et al. Centralised electricity production from winter cereals biomass grown under central-northern Spain conditions: Global warming and energy yield assessment // Applied Energy, February 2014, vol. 114, P. 737 - 748. 


\section{ENERGY AND ECOLOGY ANALYSIS OF BIOENERGY TECHNOLOGIES. PART 2}

Geletukha G.G., Zheliezna T.A., Drozdova O.I.

Institute of Engineering Thermophysics

of the National Academy of Sciences of Ukraine, vul. Zhelyabova, 2a, Kyiv, 03680, Ukraine

The paper covers the issue of energy efficiency of biogas production and production of first generation liquid biofuels. Detailed analysis of studies on energy and ecology efficiency of bioenergy technologies based on the life cycle assessment is performed. The results of GHG emissions calculations show that all solid biomass installations and most of biogas plants meet current and future requirements of the Directive 2009/28/EC - greenhouse gas emissions reduction caused by their operation is $>60 \%$. As for liquid biofuels, most parameters of the first generation biodiesel and bioethanol meet current requirements of the Directive 2009/28/EC, some meet the requirement that enters into force from 2017 (min. $50 \%$ ), and almost all parameters exceed the requirements that will be applied from 2018 (min. $60 \%$ \%). For the second generation biofuels results are much better, greenhouse gas emissions reduction amounts to $80 . .95 \%$. Biogas as transport fuel also has quite good figures on GHG emission reduction, which are over $80 \%$. References 8, Tabl. 6, Fig 1.

Key words: biomass, biogas, biofuel, bioenergy technologies, energy analysis, energy yield coefficient, life cycle assessment, greenhouse gases.

1. Daniela Dressler, Achim Loewen, Michael Nelles. Life cycle assessment of the supply and use of bioenergy: impact of regional factors on biogas production // The International Journal of
Life Cycle Assessment. - November 2012, vol. 17, issue 9, P. $1104-1115$.

2. M. Berglund, P. Börjesson. Energy analysis of biogas systems. Proc. of 2nd World Conference on Biomass for Energy, Industry and Climate Protection, 10-14 May 2004, Rome, Italy, P. $687-690$.

3. J. Malca, F. Freire. Life cycle energy analysis for bioethanol: allocation methods and implications for energy efficiency and renewability. Proceedings of 17 th International Conference on Efficiency, costs optimization simulation and environmental impact of energy and process systems, 7-9 July 2004, Mexico.

4. Bilodid V.D., Tarasenko P.V. Some calculations on the energy efficiency of biofuels // Problems of General Energy. - 2008, №18, P. 34 -39 . (Rus.)

5. Thomas Nussbaumer, Michael Oser. Evaluation of biomass combustion based energy systems by cumulative energy demand and energy yield coefficient. Report for International Energy Agency and Swiss Federal Office of Energy, 2004.

6. Directive $2009 / 28 / E C$ of the European Parliament and of the Council on the promotion of the use of energy from renewable sources and amending and subsequently repealing Directives 2001/77/EC and 2003/30/EC.

7. Neil Bird, Annette Cowie, Francesco Cherubini, Gerfried Jungmeier. Using a Life Cycle Assessment approach to estimate the net greenhouse gas emissions of bioenergy. Report on IEA Bioenergy Task 38.

8. C.M. Sastre, E. Maletta, Y. Gonzalez-Arechavala et al. Centralised electricity production from winter cereals biomass grown under central-northern Spain conditions: Global warming and energy yield assessment // Applied Energy, February 2014, vol. 114, P. 737 - 748.

Получено 21.05.2014

Received 21.05.2014 